\title{
Claudins in lung diseases
}

\author{
Ylermi Soini
}

\begin{abstract}
Tight junctions are the most apically localized part of the epithelial junctional complex. They regulate the permeability and polarity of cell layers and create compartments in cell membranes. Claudins are structural molecules of tight junctions. There are 27 claudins known, and expression of different claudins is responsible for changes in the electrolyte and solute permeability in cells layers. Studies have shown that claudins and tight junctions also protect multicellular organisms from infections and that some infectious agents may use claudins as targets to invade and weaken the host's defense. In neoplastic diseases, claudin expression may be up- or downregulated. Since their expression is associated with specific tumor types or with specific locations of tumors to a certain degree, they can, in a restricted sense, also be used as tumor markers. However, the regulation of claudin expression is complex involving growth factors and integrins, protein kinases, proto-oncogens and transcription factors. In this review, the significance of claudins is discussed in lung disease and development.
\end{abstract}

\section{Tight junctions}

Tight junctions are membranous structures present in epithelial, endothelial and mesothelial cells [1,2] They form barriers between cells in cell layers regulating diffusion of molecules and ions through the intercellular space [3]. They also form a fence separating the apical part of the cell from other parts thus preventing membrane proteins from mixing up with each other [3]. They play a part in the formation of cellular polarity and attachment [2,3] (Figure 1). The barrier formed by the tight junctions prevents pathogens from penetrating through the epithelial layers thus serving as components of innate immunity [4]. They also participate in the immune defense by forming secluded areas such as the brain, eye or testis, where they contribute to sealing these tissues from the immune system [5,6]. Tight junctional proteins also participate in regulation of cell differentiation and proliferation [7].

Tight junctions consist on one hand of membrane proteins mediating cell to cell contacts. They include occludin, claudins, tricellulin and JAMs (junctional adhesion molecules). Scaffolding proteins on the other hand mediate signals from the surface to cytoskeletal actin filaments and activate signaling cascades of the cell

Correspondence: ylermi.soini@uef.fi

Department of Pathology and Forensic Medicine, Institute of Clinical Medicine, Pathology and Forensic Medicine, School of Medicine, University of Eastern Finland, Cancer Center of Eastern Finland, P.O. Box 1627, Fl-70211 Kuopio, Finland
[1,3]. They include ZO-1 (Zona occludens-1), ZO-2, ZO-3, MAGI-1 (membrane-associated guanylate kinase with inverted orientation-1), cingulin and MUPP1 (multi-PDZ domain protein 1) [1,3,7]. Membrane proteins are divided in two groups, those with one transmembrane domain (JAMs) and those with four (claudins, occludin, tricellulin) [7]. The membrane proteins contain sequences in their carboxyterminal end with which they can attach to the scaffolding proteins [7]. One such is the PDZ domain with which the membrane proteins bind to ZO-1, ZO-2, ZO-3 or MUPP1 proteins $[7,8]$. Scaffolding proteins, like $\mathrm{ZO}-1$ inhibit cell proliferation by binding ZONAB (ZO-1 associated nucleic acid binding protein) thus preventing its movement to the nucleus [7]. Apg-2 (Albino and pale green 2 ), a protein involved in heat shock reaction, may replace ZONAB from its association with $\mathrm{ZO}-1$ thus promoting its movement to the nucleus resulting in increased proliferation [7,9] (Figure 2). Also ZO-2 influences cell proliferation by binding to transcription factors AP-1 (Activator protein 1) and SAF-B (Scaffolding attachment factor B) [7].

\section{Claudins}

Claudins are proteins responsible for the regulation of the paracellular permeability of cells $[1,3]$. They were discovered in 1998 by Tsukida and Furuse [10] and currently 27 claudins are known to be expressed by mammals[1,11]. In humans, claudin 13 is missing [12]. Based 


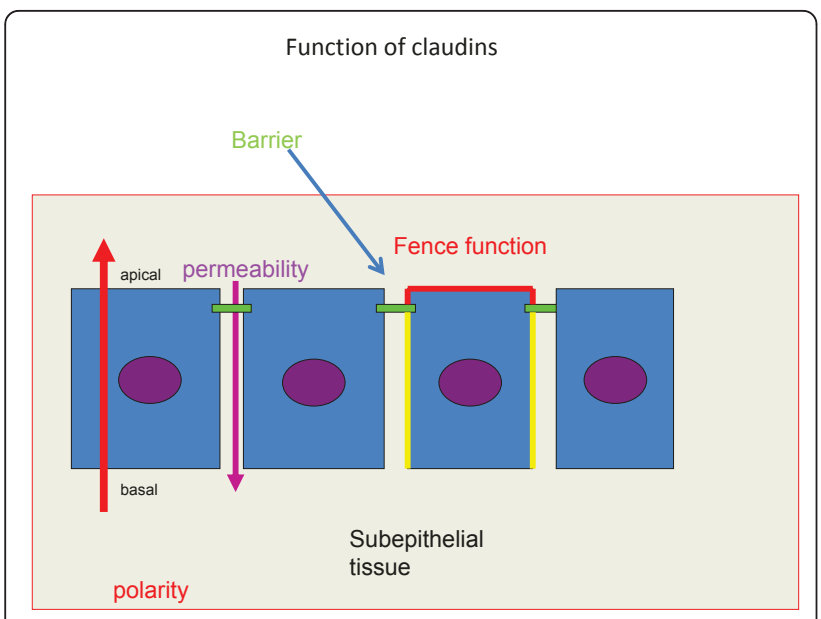

Figure 1 In an epithelial cell layer tight junctions (marked by green) regulate the permeability of solutes and ions through the paracellular space (a violet arrow pointing downwards). Thus they function as barriers of the paracellular space and also prevent pathogens from reaching the subepithelial tissues. Tight junction also takes part in determining the polarity of epithelial cells (red arrow). Since they are located in the apicolateral part of the cell membrane they separate the apical part of the cell membrane (red) from the lateral part (yellow) preventing membrane proteins from these parts of mixing up with each other (the fence function).

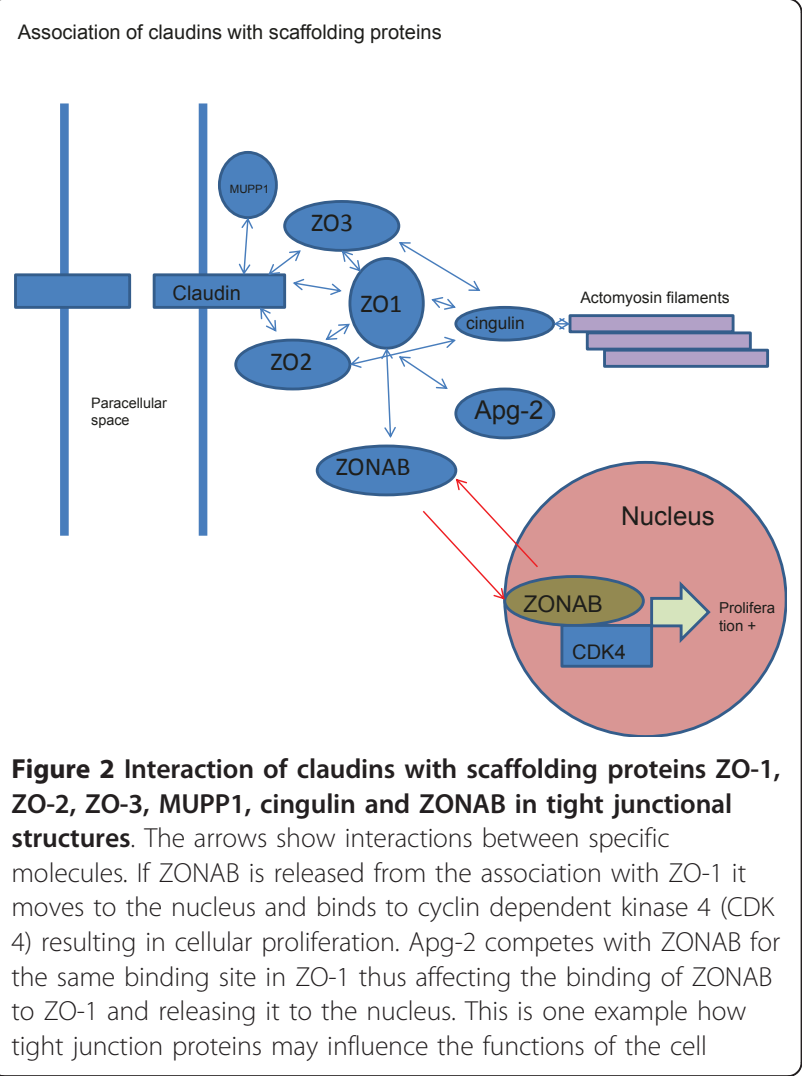

on their sequence similarity they are divided into classic and non-classic claudins $[1,12]$. The former include claudins 1-10,14, 15, 17 and 19 and the latter claudins 11-13, 16, 18 and 20-24 [1]. Claudins have four transmembrane domains, between these there are two extracellular loops (EL1 and EL2) and between inner transmembrane domains there is a short 20-residue intracellular loop [1,12] (Figure 3). The intracellular carboxyterminal part contains the PDZ domains by which scaffolding proteins attach to claudins $[1,12]$. The larger EL1 loop influences paracellular charge selectivity and the smaller EL2 binds the claudin molecule to the corresponding one in the neighbouring cell [12]. Claudins can associate with the same claudin or another one on the same cell membrane or with the claudin of the neighbouring cell $[1,13]$. Heterodimerization between claudins can take place only between specific claudins, for instance between claudin 1 and 4 but not between claudin 1 and 2 [13]. In general, claudins 2, 7, 10, 15 and 16 increase paracellular cation permeability by forming pores in the tight junctions whereas claudins 4 , $5,8,11,14$ and 18 have a sealing function [1].

\section{Claudins in normal lung}

Claudins 1, 3, 4, 5, 7, 8 and 18 are expressed in human bronchi and bronchioles but there are discrepant reports of the expression of claudin 2 [14-18]. In immunohistochemical studies on formalin fixed human lung tissue bronchial epithelial cells expressed claudins $2[17,18]$. Similarly, claudin 2 has been detected in mouse lung [15]. However, in mRNA analysis of bronchial tissues it was not found [14]. Claudin 2 has been detected in skin

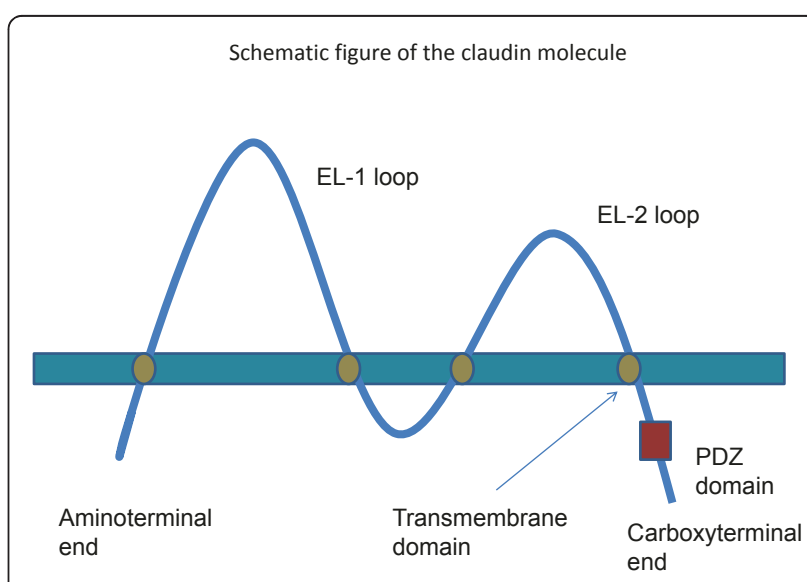

Figure 3 Claudins are membranous proteins harbouring two extracellular loops (EL-1 and EL-2) and one small intracellular loop. The larger EL-1 loop regulates solute permeability and charge selectivity while the smaller EL-2 loop establishes contacts with the neigbouring cell. There are four transmembrane domains in claudin molecules. By the carboxyterminal part the claudin molecule attaches to the scaffolding proteins of the tight junctions. 
squamous cells and in enterocytes where it takes part in absorption of D-vitamin from the intestine $[19,20]$. High amounts of claudin 2 mRNA are found in kidney, pancreas, stomach and liver tissues while neural and lymphatic tissues lacked expression [21]. In the study of Aung et al trace amounts of claudin 2 were found in the lung but the source of the expression was not determined [21].

Claudin expression appears to be the same in larger and smaller bronchi and there is no variation in claudin expression as has been found in different parts of the gut or kidney tubular segments [14,22,23]. Quantitative differences may, however be present and claudins appear to be located not only in the apical region of cells but also on the lateral membrane [14]. Claudin 5 is considered to be expressed mainly in endothelial cells and it takes part in the formation of the blood brain barrier [24]. It appears to be involved in the sealing function of endothelial barriers in others sites such as blood retinal or blood testis barrier $[5,6]$. When claudin 5 was overexpressed in bronchial tranfectant cells it, however, made the epithelium leakier while claudins 1 and 3 made it tighter [14]. In rat alveolar cells, EGF stimulation increased the transmembrane resistance with an increased claudin 4 or 7 protein expression while claudins 3 and 5 were associated with a leakier phenotype [25]. Paradoxically then, claudin 5 appears to induce loosening of the barrier both in bronchial and alveolar cells $[14,25]$.

In immunohistochemical studies on human alveolar cells, claudins 3,4 and 7 have been detected in type 2 alveolar cells while type 1 alveolar cells were negative $[17,18]$. Rat alveolar epithelial cells expressed claudin 3, 4 and 7 mRNA but claudin 1 or claudin 5 mRNA were not found even though claudin 5 was found in western blot analysis in alveolar cells [25]. Rat type 2 alveolar cells express more claudin 3 and type 1 cells more claudin $7[16,26]$. Thus there are inconsistencies regarding claudin expression also in alveolar cells detected by immunohistochemistry or mRNA analysis which may be species specific, partly due to the method used or may reflect extended half lives of proteins compared to RNA. Inconsistent results between protein and mRNA levels of claudins 1, 3 and 7 have also been detected in alcohol induced lung changes in rats where the protein expression of these claudins increased while the mRNA levels stayed the same [27]. In studies on claudin mRNA expression in human lung tissues claudins 6, 9, 10, 11, 15 or 16 have not been detected $[14,16]$. Expression of claudins in lung cells has been compiled in Table 1.

\section{Claudins in embryonic development of the lung}

Claudins are involved in embryogenesis and organogenesis and changes in their expression can be seen in the
Table 1 Claudin expression in bronchial, alveolar and mesothelial cells

\begin{tabular}{lll}
\hline & $\begin{array}{l}\text { Claudin protein or mRNA } \\
\text { expression }\end{array}$ & Reference \\
\hline Bronchial cells & $\mathbf{1}, 2, \mathbf{3}, \mathbf{4}, \mathbf{5}, \mathbf{7}, 8^{*}, 1^{*}$ & {$[14-18,81,82]$} \\
Alveolar cells & $2, \mathbf{3}, \mathbf{4 , 5}, \mathbf{7}, 18 \mathbf{1}^{*}$ & {$[15-18,25-27,81]$} \\
type 2 & $1,3,4,5,7,8,18$ & {$[27,68,26]$} \\
$\begin{array}{l}\text { Alveolar cells } \\
\text { type 1 }\end{array}$ & {$[104,107]$} \\
Mesothelial cells & $1,2,3,5,7$ & \\
\hline
\end{tabular}

* = only mRNA expression found

bold = both mRNA and protein expression found

normal text $=$ only protein expression found

organogenesis of the gut and kidney [23,28]. Claudin 15 serves as a target for tcf2 gene in zebrafish creating one lumen instead of multiple ones [29]. Interestingly, claudin 15 knockout mice develop a megaintestine [30]. In organogenesis, claudin expression is turned off in cells taking part in epitheliomesenchymal transition [31]. In embryonic development claudins regulate cellular integrity, and create hydrostatic pressure differentials maintaining integrity of cystic compartments [31,32]. Additionally, claudin 1 may have a role in right-left patterning of the embryonic tissues [31]. In Xenopus, claudin 5 is required for heart development [33].

There are five stages in lung organogenesis. In the embryonic period, the tracheal bud forms. The pseudoglandular and canalicular periods are characterized by branching morphogenesis giving rise to the bronchial three while during the saccular and alveolar periods the alveoli form[17]. In investigations on claudin expression during these stages claudins $1,3,4,5$ and 7 can be detected in bronchial epithelium during the pseudoglandular and canalicular periods [17]. Pretype alveolar cells express claudins 3, 4, 5 and 7 but not claudin 1 [17]. In saccular and alveolar periods claudin 5 is lost from alveolar cells but weakly present in bronchial epithelial cells. Claudins 3, 4 and 7 show strong positivity in bronchial and alveolar cells while claudin 1 is negative in alveolar pneumocytes [17].

Compared to lung development also kidney ureters develops by first forming an ureteral bud followed by branching morphogenesis. Like in the lung tracheal budding ZO-1 is required in ureter bud formation of rat tissues [28]. Branching morphogenesis is promoted by ezrin which is activated by growth factors EGF (Epidermal growth factor), HGF (Hepatic growth factor) or interleukin-1alpha by tyrosine phosphorylation. MTMMP1 (Membrane type matrix metalloproteinase 1) and MMP2 (Matrix metalloproteinase 2) are secreted on tips of the epithelial branches and proliferation is higher in epithelial cells in those areas [28]. Proteins of adherence junctions such as E-cadherin, are expressed a bit 
earlier, however there is a gradual increase of claudin 3 and $\mathrm{ZO}-1$ from day 3 to 5 in cultured ureteric buds [28]. Anatomically, the branching morphogenesis in the lung differs from the ureteric development in that in the ureteral development there is no lateral branching [28]. Also EGF (Epidermal growth factor) seems to be important for lung organogenesis, deletion of EGFR (Epidermal growth factor receptor) leads to impaired branching and deficient alveolisation, and pneumocytes remain immature [34].

Prealveolar fetal alveolar lung cells express claudin-1, $3,4,5,7,9,10$ and 18 mRNAs [16]. mRNAs for occludin, JAM-1, ZO-1, ZO-2, and ZO-3 are also present [16]. In experimental models on alveolar cell differentiation undifferentiated fetal alveolar epithelial cells increase their transepithelial resistance under the influence of cell culture medium containing dexamethasone, 8-bromo-cAMP and isobuthylmethylxanthanine and transform to type 2 alveolar cells at the same time increasing the claudin 5 and $18 \mathrm{mRNA}$ levels and decreasing claudin 1 mRNA [16]. On the other hand, EGF stimulated fetal alveolar type 2 cells show a decrease in claudin 5 and 3 mRNA but an increase in claudins 4 and 7 mRNA while increasing their transepithelial resistance and transforming to type 1 cells [25]. While such in vitro models may differ from physiological conditions, changes in claudin expression apparently modulate or follow phenotypic changes in lung bronchial or alveolar cells during organogenesis. Such studies also emphasize EGF's role in lung alveolar development.

\section{Potential roles of claudins and tight junctions in lung disease}

Tight junctions are important for lung defense since they function as a barrier for pathogens and other exogenous compounds preventing their penetration into the interstitial tissues. Tight junctions may thus be considered as a part of the innate immune system. The epithelial barriers of bronchi are, however, relatively leaky with a comparatively low transmembrane resistance of approximately $100 \Omega \mathrm{cm} 2$ compared to endothelial cell junctions of the blood brain barrier which have a 1500$2000 \Omega \mathrm{cm} 2$ barrier resistance $[14,35]$. The thickness of the tight junctional belt in airway epithelia varies from $0.27 \mu \mathrm{m}$ to $0.37 \mu \mathrm{m}$ depending on the cell type [36]. There are reports of fragmentation and thinning of the tight junctional belt in diseases such as asthma and focal proliferations and thinnings are described in lung neoplasia such as bronchioloalveolar carcinoma [36]. Such changes are also seen in cell line studies induced by cytokines [37]

Lungs are exposed to several pathogens and noxious stimuli which may influence paracellular permeability of bronchial airways, alveolar cells or endothelial barriers in alveolar walls. Tobacco smoke makes tight junctions leakier [36]. Carcinogenic compounds such as bentzpyrene and 4-(methylnitrosamino)-1-(3-pyridyl)-1-butanone (NNK) influence claudin synthesis by upregulating transcription factors like twist, snail or ZEB1 [38,39] resulting in downregulation of E-cadherin and claudins. Exposure of lung BEAS-2B cells and cancer cell lines to tobacco smoke leads to changes in claudin expression [40]. In bronchial cells sampled from smoking COPD patients and healthy smokers claudins and other tight junction genes are downregulated [41]. Tobacco smoke also induces the formation of reactive oxygen species. In kidney epithelial MDCK (Madine-Darby canine kidney strain) II cells, exposure to hydrogen peroxide leads to bimodal changes in the transepithelial barrier permeability with activation of ERK1/2 and p38 kinases, and a decrease in occludin, claudin 1 and claudin 2 levels [42]. Such changes could also make the bronchial and alveolar epithelium leakier and the airways more vulnerable to damage caused by pathogens causing irritation and chronic infection. On the other hand, an increase in claudin 2 expression leads to lower transepithelial resistance in MDCK I and II cells and formation of paracellular water channels $[43,44]$. Generally air pollutants influence the barrier function of airway epithelium. Particulate matter of less than $10 \mu \mathrm{m}$ in diameter decreases the transepithelial potential in airway epithelial cells causing internalization of occludin and its dissociation from ZO-1 [45].

Inflammation may affect the barrier function of tight junctions. Several integrins and growth factors produced by inflammatory cells influence synthesis or organization of tight junction components leading to enhanced permeability and exposure of tissues to antigens $[15,46,47]$. Increased permeability of tight junctions is one factor lying behind the pathophysiology of colitis ulcerosa and Crohn's disease [47]. Also in chronic bronchitis and asthma airway epithelial cells are exposed to chronic stimulation by integrins and growth factors predisposing the bronchial wall to dysregulation of the epithelial barrier function further provoking the chronic infection [46,48-50].

Pathogens may influence tight junctions in two ways. Several bacteria and viruses lower the transepithelial resistance by decreasing the expression of tight junctional proteins making it easier for pathogens to penetrate the tissues. Rhinovirus downregulates the transepithelial resistance of nasal epithelial cells by lowering the mRNA expression of claudin 1, ZO-1, E-Cadherin and occludin [51]. HIV-1 decreases the transepithelial resistance in enterocytes and genital epithelial cells by disrupting claudins 1,2 , 4, occludin and $\mathrm{ZO}-1$ in tight junctions and lowering mRNA expression of claudins 1 , $2,3,4,5$, occludin and ZO-1 by cytokine involved 
mechanisms allowing penetration of bacteria and viruses through the leaky barriers [52]. Rotavirus in known to loosen tight junctions in gut epithelial cells by decreasing expression of claudin 3, occluding and ZO-1 [53]. Yersinia enterocolica causes a redistribution of claudins 3, 4 and 8 in colonic HT29/B6 cells with a lowering of transepithelial resistance and diminution of the protein expression of claudins 2, 3, 8 and 10 and ZO-1 [54]. Aggressive strains of $E$ Coli cause dissociation of claudin 1, ZO-1 and occludin from cell membranes along with a decrease in electrical transmembrane potential [55]. Helicobacter pylori causes disruption of claudin 4 expression in tight junctions and its movement to the cytosol in gastric epithelial cells and lowering of claudin 4 protein levels, an effect which is dependent on IL-1 $\beta$ [56]. On the other hand, claudins may be used as receptors or co-receptors in the invasion of bacteria and viruses to cells and tissues. Claudins 1, 6 and 9 serve as a co-receptors for hepatitis $\mathrm{C}$ for invading liver and endothelial cells $[57,58]$. Claudin 1 also promotes dengue virus entry to cells [59]. Claudins also serve as receptors for some bacterial toxins. A well known example is Clostridium perfringens enterotoxin (CPE) which binds to claudin 3 and 4 [60]. In experimental studies this has been used to destroy claudin 3 and 4 expressing cancer cells with chemical modifications of the toxin [60]. Interestingly, CPE has also been successfully used to destroy metastatic cells expressing claudin 4 in murine tissue [61]. Unfortunately, claudin 4 is many times downregulated in metastatic tissues such as metastatic breast carcinoma [62] or carcinoma metastasis to the lung [63]. The frequent associations of claudins as means and targets for spread of infections could predict putative polymorphisms in claudin molecules. Indeed, 50 variations have been found in the claudin 1 gene region some of which alter susceptibility to hepatitis C infection [64].

Mechanisms of pathogen entry and its association with claudins have not been so extensively studied in the respiratory tract. It, however, appears probable that similar mechanisms apply to airway epithelia. Matrix metalloproteinase 9 (MMP 9)decreases epithelial barrier function in bronchial cells, and increases their vulnerability to adenovirus infection [65]. The cells show disruption of regular membranous staining pattern of claudin 1 and occludin and internalization of reactivity following MMP9 treatment which could be restored by tissue inhibitor of matrix metalloproteinase 1 (TIMP1) [65]. Pseudomonas aeruginosa has been shown to invade airway epithelial barriers by destroying tight junctions [66]. Interestingly, Plasmodium falciparum malaria affects lung endothelial cells by relocation of ZO-1 from the plasma membrane and downregulation of claudin 5 [67]. Thus also parasite infections may be associated with tight junctional changes in the pulmonary cells.

\section{Claudins in lung injury and inflammation}

ARDS (Acute respiratory distress syndrome) is due to injury of alveolar cells the reasons of which may be multiple including septic infections and toxic chemicals. Such injury leads to edema due to leakage of alveolar epithelial cells. Since claudins regulate paracellular permeability of cell layers evidently changes in claudin expression are involved in such disease. There are no morphological studies on claudin expression by human tissues in ARDS. Evidence of tight junctional protein changes in ARDS can be obtained from animal experiments or cell culture studies. In alveolar cells cultured from septic rat lung a decrease of claudin 4, claudin 18 and occludin was found associated with a decrease in transmembrane resistance [68]. In ventilator-induced lung injury in mice the mRNA expression of claudin 4 increased after 3 hours [69]. Such a phenomenon appears to be an adaptive mechanism to make the alveolar layers tighter, since blocking specifically the mRNA synthesis of claudin 4 by siRNA or CPE lowers the transmembrane potential [69]. Similar results come from experimentally induced pancreatitis in rats where the mRNA levels of claudin 4 , claudin 5 and occludin decreased due to pancreatitis induced lung injury but increased after administration of emodin, a chemical suggested to enhance epithelial barrier function [70]. Such data emphasize especially the role of claudin 4 in combating the abrogation of alveolar cell permeability in lung injury. Also the expression of claudin 5 is important for endothelial cell tightness and vascular permeability. Acrolein present in tobacco smoke may cause lung injury by influencing claudin 5 expression in endothelial cells and mice more resistant to acrolein have a better survival due to their increased expression of claudin 5 mRNA transcripts [71].

Interestingly, protein kinase $\mathrm{C}$ delta inhibitor appeared to inhibit sepsis induced lung injury, such as disruption of lung tissue or development of edema [72]. In nasal epithelial cells treatment of cells with protein kinase $\mathrm{C}$ activator 12-O-tetradecanoylophospho-13-acetate led to an increased transepithelial electrical resistance and upregulation of claudin 1, ZO1, ZO2 and occludin [73]. It was shown that the upregulation of the tight junctional proteins was due to activation of PKC lambda and theta partly induced by the transcription factor GATA 3 [73]. In fact, phosphorylation of threonine sites in claudins by PKC or PKA may dislocate claudins from cellular membranes resulting in changed tight junctional properties [1].

Also in lung inflammation alterations in alveolar cell permeability play a role. In experimental studies on 
mice where lung inflammation was induced by carrageenan disruption of claudin 2 , claudin 4 and claudin 5 staining and ZO-1 was observed on cell membranes [15]. Such disruption was partly reversed by blocking TNF $\alpha$ suggesting that TNF $\alpha$-induced chemotaxis of inflammatory cells might contribute to attenuation of tight junctional permeability in lung inflammation [15]. Additionally, alcohol which provokes patients to lung inflammation and ARDS was shown in experiments on rats to induce changes in claudin expression of alveolar epithelial cells [27]. Chronic alcohol ingestion of rats led to a decrease of claudin 1, 3 and 7 mRNA and protein expression and an increase in claudin 5 mRNA in alveolar epithelial cells resulting in an increased leakiness of tight junctions in the lung [27]. Additionally, inflammatory mediators like IL- $1 \beta$ or IL- 6 decrease claudin 3 and 4 levels in amniotic membranes of mice making them more permeable [74].

Respiratory distress leads to local hypoxia of the lung. Hypoxia induces cytoskeletal disruption of alveolar epithelial cells and decreases $\mathrm{ZO}-1$ protein levels dislocating occludin from the cell membrane [75]. Alveolar epithelial cells do not show changes in claudin 3 or 5 protein expression, however [75]. Claudin 5 is known to influence the permeability of endothelial cells. In experiments performed on mice bEND.3 (brain-derived endothelial) and retinal endothelial cells, suppression of claudin 5 mRNA leads to a decrease in transepithelial resistance of these cells [76]. On the other hand, in experimental murine renal ischemia-reperfusion injury there was a significant upregulation of claudin $-1,-3$, and -7 genes and a slight downregulation of claudin-2 [77]. Additionally, when both of these cells suffer from hypoxia a decrease in claudin $5 \mathrm{mRNA}$ and a lowering of transepithelial resistance was detected [76].

There are only a few studies on the influence of inflammation on claudin expression in bronchial cells. In well differentiated human airway epithelial cells (HAE) from cystic fibrosis (CF) and non-CF patients, combined treatment with IL-1 $\beta$ and TNF $\alpha$ led to a decrease in transmembrane potential and tight junctional barrier function, the changes appearing more rapidly in CF cells [37]. In analysis of airway epithelial cells the expression of claudins 1 and 4 were not altered, however, there was a decrease in the protein expression of ZO1 and JAM and upregulation of hyperphosphorylated occludin and ICAM1 [37]. The influence of these cytokines appeared to be mediated by PKC/lambda [37].

\section{Claudins in interstitial lung disease}

Interstitial lung diseases are characterized by chronic inflammation, fibrosis and damage to the lung parenchyma [78]. They consist of seven entities which are classified both by histology and clinicopathologic features
[78]. In interstitial lung diseases, reports of claudin expression in UIP (Usual interstitial pneumonia) are present [18]. Changes in claudin expression mainly involve the regenerative alveolar cells or cells which have been replaced by metaplastic epithelia. In UIP regenerative metaplastic alveolar, squamous or bronchial epithelium shows strong reactivity for claudins 1, 2, 3, 4 and 7 compared to normal alveolar cells where only claudins 3, 4 and 7 are present [18]. There is a weaker reactivity for claudin 5 in such regenerative cells. In sarcoidosis, metaplastic regenerative epithelium displays a similar kind of reactivity in metaplastic cells as in UIP [18]. The formation of metaplastic epithelium in UIP probably is related to chronic inflammation and secretion of growth factors and integrins in the disease [78]. A different pattern of claudin expression in regenerative metaplastic cells compared to alveolar cells would lead to focal changes in the permeability of alveolar walls which is probably harmful for the function of the lung. There is also increased vascularity, neovascularisation and increased secretion of angiogenic factors in UIP [18]. Endothelial cells of blood vessels display intensive expression for claudin 5. According to some reports VEGF may upregulate claudin 5 [79]. Such increased staining may then be based on increased secretion of VEGF in UIP. Expression of claudins in different lung pathologies has been compiled in Table 2 .

\section{Lung tumors}

Lung carcinoma cells contain tight junctions and their number is inversely associated with patient prognosis and aggressivity [80]. In lung tumor cell lines, variable expression of claudins $1,2,3,4$ and 7 is found [40]. In studies on lung tumor material different histological tumor types vary in their claudin expression showing up- or downregulation of different claudins compared to normal bronchial cells or lung tissue [40,81-83]. In the study of Moldway et al small cell lung carcinomas show a 16 fold higher level of claudin 3 mRNA expression than normal lung tissue [82]. Claudin 4 mRNA is upregulated to 3-4 fold level in squamous, adenocarcinoma and small cell carcinoma compared to normal lung [82]. Both adeno- and squamous cell carcinoma showed a slight downregulation of claudin 1 mRNA compared to normal lung and squamous cell carcinomas had a 2.7 fold level of claudin 1 mRNA than adenocarcinomas [82]. Paschoud et al found an increase in claudin 5 and a decrease in claudins 3,4 and 7 mRNA in squamous cell carcinoma compared to normal bronchial cells and an increase in claudin 1 and a decrease in claudin 5 compared to lung parenchyma [81]. Compared to bronchial cells claudins 1,3 and 4 and 7 were decreased and claudin 5 mRNA increased in adenocarcinoma while when compared to lung 
Table 2 Claudin expression changes in different lung pathologies

\begin{tabular}{llllllll}
\hline & UIP* & ARDS & Inflammation & Lung SQC** & Lung AC** & Lung SCC** & Reference \\
\hline $\mathrm{CL} 1$ & $\uparrow$ & & $\leftrightarrow$ & $\uparrow \leftrightarrow$ & $\leftrightarrow \leftrightarrow$ & $\leftrightarrow$ & {$[37,18,81,82,47,76,77]$} \\
$\mathrm{Cl} 2$ & $\uparrow$ & & $\downarrow$ & $\leftrightarrow \leftrightarrow$ & $\leftrightarrow \leftrightarrow$ & $\leftrightarrow$ & {$[15,18,81,82]$} \\
$\mathrm{CL} 3$ & $\uparrow$ & & $\downarrow$ & $\leftrightarrow \leftrightarrow$ & $\uparrow$ & $\uparrow$ & {$[18,81,82,82]$} \\
$\mathrm{CL} 4$ & $\uparrow$ & $\downarrow$ & $\downarrow \leftrightarrow$ & $\uparrow \leftrightarrow$ & $\downarrow$ & {$[15,18,37,68-70,81,82]$} \\
$\mathrm{CL} 5$ & $\uparrow$ & $\downarrow$ & $\downarrow$ & $\downarrow$ & $\uparrow \leftrightarrow$ & $\leftrightarrow$ & {$[15,68-70,81,82]$} \\
$\mathrm{CL7}$ & $\uparrow$ & & & $\leftrightarrow \leftrightarrow$ & $1,8,81,82,82]$ \\
\hline
\end{tabular}

$\mathrm{CL}=$ Claudin; UIP = Usual interstitial pneumonia; $\mathrm{ARDS}=$ acute respiratory distress syndrome; SQC = Squamous cell carcinoma; $\mathrm{AC}=\mathrm{Adenocarcinoma;} \mathrm{SCC} \mathrm{=}$ Small cell carcinoma

* $=$ arrows represent metaplastic alveolar cells

${ }^{* *}=$ qtRNA results compared with lung tissue expression

parenchyma claudin 4 mRNA was increased but claudin 5 decreased [81].

In immunohistochemical studies significant differences have been detected in claudin 3 expression between squamous cell and adenocarcinomas the latter displaying stronger expression $[40,82,83]$. Some studies also report significant differences in the expression of claudin 1, 4, 5 and 7 between these two tumor groups $[81,82]$. In the study of Paschoud et al squamous cells and adenocarcinomas could be discriminated by the expression of claudins 1 and 5 because adenocarcinomas displayed strong positivity for claudin 5 and weak positivity for claudin 1 , while the opposite could be detected in squamous cell carcinomas [81]. Chao et al studied claudin 1 expression in adenocarcinoma and found that a low expression of claudin 1 was associated with a worse survival in these tumors both by immunohistochemistry and mRNA expression [84]. Transfection of claudin 1 into CL1-5 lung carcinoma cells changed the cells to less invasive, less metastatic and less mobile, and their morphology changed to a more epithelial one [84]. Such changes could also be reversed by blocking claudin 1 mRNA expression by siRNA. Oligonucleotide microarray analysis showed a twofold change in 773 genes due to claudin 1 overexpression involving different cellular functions associated with signaling cascades, cellular associations, apoptosis and cytoskeletal regulation. They, however, found that claudin 1 overexpressing cells were able to activate MMP2 [84]. Similar results of claudin expression on MMP activities have been detected in other cell lines. In colon carcinoma $\mathrm{CaCo}-2$ cells, invasion induced by claudin 4 overexpression was due to activation of both MMP2 and MMP9 the mRNA expression of which also increased at the same time [85]. Claudin 5 along with claudins 2, 3 and 4 has been shown to activate matrix metalloproteinases [86]. Claudin overexpression in cancer cells may thus be one factor promoting tumor spread.

The variable expression of claudins in histologically different lung tumor types may be related partly to the cell type it originates from [83]. On the other hand, several growth factors and integrins modify claudin expression and they expression may vary in different types of lung tumors. EGF, for instance, inhibits claudin 2 expression while simultaneously increasing claudin 1 , 3 and 4 expression and the transepithelial resistance without affecting the levels of occludin or ZO-1 in canine kidney cells [87]. In pneumocytes EGF upregulates claudins 4 and 7 while 3 and 5 are decreased [25]. Activating EGFR mutations are known to exist in nonsmall cell lung carcinoma and especially in adenocarcinoma and bronchioloalveolar carcinoma[88]. In line with this, claudins 1 and 4 show a high expression in lung adenocarcinomas and bronchioloalveolar carcinomas and claudin 2 and 5 are lower [40,82]. Small cell lung carcinomas also display a higher expression of claudin 2 than adenocarcinomas [83]. Another mutation common to lung cancer is K-Ras [88]. Such mutations are present $15-30 \%$ of non small cell carcinomas [88]. In kidney cells, overexpression of ras leads to claudin 1, 4 and 7 overexpression while claudin 2 decreases and claudins 3 and 5 remain the same [89]. Similarly, some non-small cell carcinomas have PTEN (phosphatase and tensin homologue) mutations [90]. Inactivation or mutations of PTEN leads to activation of PKB (Protein kinase B) resulting in increased cell proliferation and inhibition of apoptosis [91]. Knockdown of PTEN has been shown to lead to a loss of polarization in colon carcinoma cells and strong downregulation of claudins $1,3,4$ and 8 [92]. Small cell carcinomas and large cell neuroendocrine carcinomas, however, express c-kit, and they harbor c-myc amplifications and p53 and ras mutations, and loss of p16 and RB expression and their influence on claudin expression is not known [93]. Additional, several cytokines influence claudin expression and barrier function of epithelial cells and may surely influence also the expression of claudins in lung carcinomas [47].

EMT (Epitheliomesenchymal transition) is a process where tumor cells attain mesenchymal features which make it easier for them to invade and metastasize $[94,95]$. It is regulated by transcription factors such as snail, slug, twist and zeb1 [94-96]. In mouse mammary epithelial cells snail induced EMT and at the same time 
downregulated claudins 3, 4 and 7, occludin and E-cadherin [97]. In lung carcinoma there was an inverse association between zeb1 and claudins 1 and 2 and between twist and claudin 5 [63]. Metastatic tumors to the lung also showed an inverse association between claudins 5 and 7 and twist [63]. These results show that a part of claudin expression is regulated by EMT associated transcription factors and that claudins are involved in EMT.

Also different PKCs which regulate claudin phosphorylation are overexpressed in cancer and may cause dysregulation or relocation of claudins in tumor cells [98]. $\mathrm{PKC} \varepsilon$ is considered an oncogene and influences cellular motility and ras expression, and it is upregulated in lung and breast cancer [98]. PKC and PKA influence subcellular distribution of claudin 1 in melanoma cells [99]. PKC $\alpha$ phosphorylates claudin 5 causing its disappearance from cell membrane [100]. On the other hand, phosphorylation of serine 194 of claudin 4 by aPKC is required for tight junction formation in keratinocytes [101]. Claudin phosphorylation may also affect barrier junction permeability without changes in claudin distribution [101].

Claudins are in contact with scaffolding proteins like ZO-1, ZO-2 and ZO-3 and through them with the cellular cytoskeleton [102]. ZO-1 has been shown to recruit the transcriptional factor ZONAB from cytoplasm thus preventing its movement to the nucleus where it promotes cell proliferation. ZO-2, on the other hand, is able to bind AP-1 [103]. How the expression of different claudins influences the functions of such zona occludens proteins is not known but it is possible that in cancer cells the relation between claudins and zona occludens and other scaffolding proteins is deranged leading to a dysregulation of transcription factors such as ZONAB or AP-1. Clearly more research is needed to understand the functions and consequences of claudin expression in lung cancer.

Because claudins 3 and 4 are overexpressed in adeno, squamous and small cell carcinomas [40,81-83] they might be susceptible to CPE-mediated treatment. In a recent publication Yao et al created a modified CPE protein containing segments of pseudomonas aeruginosa enterotoxin A [104]. Treatment of cell lines containing claudin 4 induced apoptosis and cell destruction in them[105]. CPE also causes dislocation of claudin 4 from the tight junction in ovarian carcinoma cells and sensitizes them to chemotherapeutic drugs [105]. This effect is achieved by using a modulated C-terminal fragment of the CPE molecule in the treatment which is able to bind to claudin 4 and cause tight junctional loosening but harbours no toxic effects of the N-terminal part of the molecule thus enabling a better influx of chemotherapeutic agents to the cancer tissue (105). Such CPE mediated treatment could also be one option in treatment of claudin 3 or 4 positive lung cancer.

\section{Mesothelial cells and mesotheliomas}

Mesotheliomas are malignant tumors with an aggressive behavior. In pleural biopsies taken for malignant pleural disease, there is often diagnostic difficulty to distinguish mesotheliomas from metastatic adenocarcinomas or reactive mesothelial cells. Several markers, such as calretinin, DJ2-40, TTF1 and CEA, can be used in differential diagnosis [106]. Claudins have also proven to be one putative means of making a differential diagnosis between such entities [107-110].

In our study on metastatic adenocarcinomas and malignant mesotheliomas claudins $1,3,4,5$ and 7 had a lower expression in mesotheliomas suggesting that they could serve as differential diagnostic markers [107]. In mesothelioma subtypes, sarcomatoid and biphasic mesotheliomas showed less expression for claudins than epithelioid ones [107]. Non-neoplastic mesothelial cells showed expression for claudin 2 and weak expression for claudin 1, but no expression was found for claudins $3,4,5$ or 7 [107]. In effusions claudins 3 and 7 significantly distinguished malignant

Mesothelioma cells from metastatic adenocarcinoma cells [108]. Reactive mesothelial cells were negative for claudin 7 but showed infrequent claudin 1 and 3 expression. Thus also reactive mesothelial cells could be distinguished from metastatic cells in pleural effusions [108]. Metastatic ovarian carcinoma cells could also be distinguished from metastatic breast carcinoma cells by claudin 7 , and generally, ovarian, endometrioid and cervical cancer metastases could be distinguished from lung or breast adenocarcinoma [108]. In the array study by Davidson et al serous mesotheliomas showed a significantly lower expression of claudins 3, 4 and 6 than ovarian adenocarcinomas speaking for a lower level of claudins in mesothelial derived neoplasms [108]. Facetti et al determined that especially claudin 4 could be used in differential diagnosis between malignant mesothelioma and metastatic adenocarcinoma [110]. Since adenocarcinoma metastases many times express claudin 4, CPE could potentially be used in treatment of such adenocarcinoma metastases in pleural cavity since benign mesothelial cells do not express this tight junctional protein [110].

Claudins have not been studied in other disease states of the mesothelium although it could be expected that they play a role in derangements of pleural fluid homeostasis and in pleuritis. Exposure of mesothelial cell monolayers to hydrogen peroxide lowers their transepithelial resistance with a simultaneous decrease in occludin and ZO-1 expression [111]. Thus oxidative stress, involved in many diseases, such as inflammation, may be one factor causing loosening of mesothelial barriers. In line with this, a recent article showed that the levels claudins $1,3,5$ and 7 decreased and claudin 2 
increased in mesothelial cells due to pleural inflammation [112].

\section{Conclusion}

The permeability of tight junctions in epithelia is an important factor in several pulmonary diseases. Pathogens causing infections are many some of which may act by downregulating claudins or causing their deranged distribution inducing changes in tight junctional permeability allowing pathogens to invade through epithelial barriers. In lung disease the effect of such pathogens on claudin expression or cellular distribution is still mainly unelucidated and needs further research. Alteration of claudin expression also plays an important role in lung diseases such as COPD, asthma, and ARDS. Influencing alveolar or endothelial permeability by manipulation the expression of claudins (eg. claudins 4 and 5) might be future targets in the treatment of lung injury. Changes in the expression of claudins are also seen in pulmonary neoplasia reflecting complex changes in several genes related to tumor growth, spread and differentiation producing a characteristic expression patterns in histologically different tumor types. In adenocarcinomas a proposed new classification will surely also change our perspectives on assessment of claudins on the behavior of these tumors [113]. In addition to claudin 3 and 4 which may have therapeutic implications for tumor treatment in the future, claudin 18 might also be a new target for antibody mediated therapy in lung cancer [114].

\section{Authors' contributions}

YS is the sole author of the manuscript

\section{Competing interests}

The author declares that they have no competing interests.

Received: 10 February 2011 Accepted: 27 May 2011

Published: 27 May 2011

\section{References}

1. Krause G, Winkler L, Mueller SL, Haseloff RF, Piontek J, Blasig IE: Structure and function of claudins. Biochim Biophys Acta 2008, 1778:631-45.

2. Mukherjee TM, Swift JG, Henderson DW: Freeze-fracture study of intercellular junctions in benign and malignant mesothelial cells in effusions and a comparison with those seen in pleural mesotheliomas (solid tumour). J Submicrosc Cytol Pathol 1988, 20:195-208.

3. Sawada N, Murata M, Kikuchi K, Osanai M, Tobioka H, Kojima T, Chiba H: Tight junctions and human diseases. Med Electron Microsc 2003, 36:147-56.

4. Landau D: Epithelial paracellular proteins in health and disease. Curr Opin Nephrol Hypertens 2006, 15:425-9.

5. Xie J, Farage E, Sugimoto M, Anand-Apte B: A novel transgenic zebrafish model for blood-brain and blood-retinal barrier development. BMC Dev Biol 2010, 10:76.

6. Morrow CM, Tyagi G, Simon L, Carnes K, Murphy KM, Cooke PS, Hofmann MC, Hess RA: Claudin 5 expression in mouse seminiferous epithelium is dependent upon the transcription factor ets variant 5 and contributes to blood-testis barrier function. Biol Reprod 2009, 81:871-9.

7. Matter K, Balda MS: Epithelial tight junctions, gene expression and nucleo-junctional interplay. J Cell Sci 2007, 120:1505-11.
8. Jeansonne B, Lu Q, Goodenough DA, Chen YH: Claudin-8 interacts with multi-PDZ domain protein 1 (MUPP1) and reduces paracellular conductance in epithelial cells. Cell Mol Biol 2003, 49:13-21.

9. Tsapara A, Matter K, Balda MS: The heat-shock protein Apg-2 binds to the tight junction protein ZO-1 and regulates transcriptional activity of ZONAB. Mol Biol Cell 2006, 17:1322-30.

10. Furuse M, Fujita K, Hiiragi T, Fujimoto K, Tsukita S: Claudin-1 and -2: novel integral membrane proteins localizing at tight junctions with no sequence similarity to occludin. J Cell Biol 1998, 141:1539-50.

11. Mineta K, Yamamoto Y, Yamazaki Y, Tanaka H, Tada Y, Saito K, Tamura A, Igarashi M, Endo T, Takeuchi K, Tsukita S: Predicted expansion of the claudin multigene family. FEBS Lett 2011, 585:606-12.

12. Lal-Nag M, Morin PJ: The claudins. Genome Biol 2009, 10:235.

13. Günzel D, Yu AS: Function and regulation of claudins in the thick ascending limb of Henle. Pflugers Arch 2009, 458:77-88.

14. Coyne CB, Gambling TM, Boucher RC, Carson JL, Johnson LG: Role of claudin interactions in airway tight junctional permeability. Am J Physiol Lung Cell Mol Physiol 2003, 285:L1166-78.

15. Mazzon E, Cuzzocrea S: Role of TNF-alpha in lung tight junction alteration in mouse model of acute lung inflammation. Respir Res 2007, 8:75

16. Daugherty BL, Mateescu M, Patel AS, Wade K, Kimura S, Gonzales LW, Guttentag S, Ballard PL, Koval M: Developmental regulation of claudin localization by fetal alveolar epithelial cells. Am J Physiol Lung Cell Mol Physiol 2004, 287:L1266-73.

17. Kaarteenaho R, Merikallio H, Lehtonen S, Harju T, Soini Y: Divergent expression of claudin $-1,-3,-4,-5$ and -7 in developing human lung. Respir Res 2010, 11:59.

18. Kaarteenaho-Wiik R, Soini Y: Claudin-1, $-2,-3,-4,-5$, and -7 in usual interstitial pneumonia and sarcoidosis. J Histochem Cytochem 2009, 57:187-95.

19. Telgenhoff D, Ramsay S, Hilz S, Slusarewicz P, Shroot B: Claudin 2 mRNA and protein are present in human keratinocytes and may be regulated by all-trans-retinoic acid. Skin Pharmacol Physiol 2008, 21:211-7.

20. Fujita H, Sugimoto K, Inatomi S, Maeda T, Osanai M, Uchiyama Y, Yamamoto Y, Wada T, Kojima T, Yokozaki H, Yamashita T, Kato S, Sawada N, Chiba H: Tight junction proteins claudin-2 and -12 are critical for vitamin D-dependent Ca2+ absorption between enterocytes. Mol Biol Cell 2008, 19:1912-21.

21. Aung PP, Mitani Y, Sanada Y, Nakayama H, Matsusaki K, Yasui W: Differential expression of claudin-2 in normal human tissues and gastrointestinal carcinomas. Virchows Arch 2006, 448:428-34.

22. Will C, Fromm M, Müller D: Claudin tight junction proteins: novel aspects in paracellular transport. Perit Dial Int 2008, 28:577-84

23. Holmes JL, Van Itallie CM, Rasmussen JE, Anderson JM: Claudin profiling in the mouse during postnatal intestinal development and along the gastrointestinal tract reveals complex expression patterns. Gene Expr Patterns 2006, 6:581-8.

24. Nitta T, Hata M, Gotoh S, Seo Y, Sasaki H, Hashimoto N, Furuse M, Tsukita S: Size-selective loosening of the blood-brain barrier in claudin-5-deficient mice. Cell Biol 2003, 161:653-60.

25. Chen SP, Zhou B, Willis BC, Sandoval AJ, Liebler JM, Kim KJ, Ann DK Crandall ED, Borok Z: Effects of transdifferentiation and EGF on claudin isoform expression in alveolar epithelial cells. J App/ Physio/ 2005, 98:322-8.

26. Wang F, Daugherty B, Keise LL, Wei Z, Foley JP, Savani RC, Koval M: Heterogeneity of claudin expression by alveolar epithelial cells. Am J Respir Cell Mol Biol 2003, 29:62-70.

27. Fernandez AL, Koval M, Fan X, Guidot DM: Chronic alcohol ingestion alters claudin expression in the alveolar epithelium of rats. Alcohol 2007, 41:371-9.

28. Meyer TN, Schwesinger C, Bush KT, Stuart RO, Rose DW, Shah MM, Vaughn DA, Steer DL, Nigam SK: Spatiotemporal regulation of morphogenetic molecules during in vitro branching of the isolated ureteric bud: toward a model of branching through budding in the developing kidney. Dev Biol 2004, 275:44-67.

29. Bagnat M, Cheung ID, Mostov KE, Stainier DY: Genetic control of single lumen formation in the zebrafish gut. Nat Cell Biol 2007, 9:954-60.

30. Tamura A, Kitano Y, Hata M, Katsuno T, Moriwaki K, Sasaki H, Hayashi H, Suzuki Y, Noda T, Furuse M, Tsukita S, Tsukita S: Megaintestine in claudin15-deficient mice. Gastroenterology 2008, 134:523-34.

31. Gupta IR, Ryan AK: Claudins: unlocking the code to tight junction function during embryogenesis and in disease. Clin Genet 2010, 77:314-25 
32. Kollmar R, Nakamura SK, Kappler JA, Hudspeth AJ: Expression and phylogeny of claudins in vertebrate primordia. Proc Natl Acad Sci USA 2001, 98:10196-201.

33. Yamagishi $M$, Ito $Y$, Ariizumi $T$, Komazaki $S$, Danno $H$, Michiue $T$, Asashima M: Claudin5 genes encoding tight junction proteins are required for Xenopus heart formation. Dev Growth Differ 2010, 52:665-75

34. Zhang Z, Stiegler AL, Boggon TJ, Kobayashi S, Halmos B: EGFR-mutated lung cancer: a paradigm of molecular oncology. Oncotarget 2010, 1:497-514.

35. Butt $\mathrm{AM}$, Jones $\mathrm{HC}$, Abbott NJ: Electrical resistance across the blood-brain barrier in anaesthetized rats: a developmental study. J Physio/ 1990, 429:47-62.

36. Godfrey RW: Human airway epithelial tight junctions. Microsc Res Tech 1997, 38:488-99.

37. Coyne CB, Vanhook MK, Gambling TM, Carson JL, Boucher RC, Johnson LG: Regulation of airway tight junctions by proinflammatory cytokines. $\mathrm{Mol}$ Biol Cell 2002, 13:3218-34

38. Yoshino I, Kometani T, Shoji F, Osoegawa A, Ohba T, Kouso H, Takenaka T, Yohena T, Maehara Y: Induction of epithelial-mesenchymal transitionrelated genes by benzo[a]pyrene in lung cancer cells. Cancer 2007, 110:369-74.

39. Wei PL, Chang YJ, Ho YS, Lee CH, Yang YY, An J, Lin SY: Tobacco-specific carcinogen enhances colon cancer cell migration through alpha7nicotinic acetylcholine receptor. Ann Surg 2009, 249:978-85.

40. Merikallio H, Kaarteenaho R, Pääkkö P, Lehtonen S, Hirvikoski P, Mäkitaro R, Harju T, Soini Y: Impact of smoking on the expression of claudins in lung carcinoma. Eur J Cancer 2010, 47:620-630.

41. Shaykhiev R, Otaki F, Bonsu P, Dang DT, Teater M, Strulovici-Barel Y, Salit J, Harvey BG, Crystal RG: Cigarette smoking reprograms apical junctional complex molecular architecture in the human airway epithelium in vivo. Cell Mol Life Sci 2010, 68:877-892

42. Gonzalez JE, DiGeronimo RJ, Arthur DE, King JM: Remodeling of the tight junction during recovery from exposure to hydrogen peroxide in kidney epithelial cells. Free Radic Biol Med 2009, 47:1561-9.

43. Lipschutz JH, Li S, Arisco A, Balkovetz DF: Extracellular signal-regulated kinases $1 / 2$ control claudin-2 expression in Madin-Darby canine kidney strain I and II cells. J Biol Chem 2005, 280:3780-8.

44. Rosenthal R, Milatz S, Krug SM, Oelrich B, Schulzke JD, Amasheh S, Günzel D, Fromm M: Claudin-2, a component of the tight junction, forms a paracellular water channel. J Cell Sci 2010, 123:1913-21.

45. Caraballo JC, Yshii C, Westphal W, Moninger T, Comellas AP: Ambient particulate matter affects occludin distribution and increases alveolar transepithelial electrical conductance. Respirology 2011, 16:340-349.

46. Crosby LM, Waters CM: Epithelial repair mechanisms in the lung. Am J Physiol Lung Cell Mol Physiol 2010, 298:L715-31.

47. Capaldo $C T$, Nusrat $A$ : Cytokine regulation of tight junctions. Biochim Biophys Acta 2009, 1788:864-71.

48. Bottoms SE, Howell JE, Reinhardt AK, Evans IC, McAnulty RJ: TGF-Beta isoform specific regulation of airway inflammation and remodelling in a murine model of asthma. PLoS One 2010, 5:9674.

49. Morty RE, Königshoff M, Eickelberg O: Transforming growth factor-beta signaling across ages: from distorted lung development to chronic obstructive pulmonary disease. Proc Am Thorac Soc 2009, 6:607-13.

50. Górska K, Maskey-Warzechowska M, Krenke R: Airway inflammation in chronic obstructive pulmonary disease. Curr Opin Pulm Med 2010, 16:89-96.

51. Yeo NK, Jang YJ: Rhinovirus infection-induced alteration of tight junction and adherens junction components in human nasal epithelial cells. Laryngoscope 2010, 120:346-52.

52. Nazli A, Chan O, Dobson-Belaire WN, Ouellet M, Tremblay MJ, GrayOwen SD, Arsenault AL, Kaushic C: Exposure to HIV-1 directly impairs mucosal epithelial barrier integrity allowing microbial translocation. PLOS Pathog 2010, 6:e1000852.

53. Nava P, López S, Arias CF, Islas S, González-Mariscal L: The rotavirus surface protein VP8 modulates the gate and fence function of tight junctions in epithelial cells. J Cell Sci 2004, 117:5509-19.

54. Hering NA, Richter JF, Krug SM, Günzel D, Fromm A, Bohn E, Rosenthal R, Bücker R, Fromm M, Troeger H, Schulzke JD: Yersinia enterocolitica induces epithelial barrier dysfunction through regional tight junction changes in colonic HT-29/B6 cell monolayers. Lab Invest 2011, 91:310-324.

55. Strauman MC, Harper JM, Harrington SM, Boll EJ, Nataro JP: Enteroaggregative Escherichia coli disrupts epithelial cell tight junctions. Infect Immun 2010, 78:4958-64.
56. Lapointe TK, O'Connor PM, Jones NL, Menard D, Buret AG: Interleukin-1 receptor phosphorylation activates Rho kinase to disrupt human gastric tight junctional claudin-4 during Helicobacter pylori infection. Cell Microbiol 2010, 12:692-703.

57. Evans MJ, von Hahn T, Tscherne DM, Syder AJ, Panis M, Wölk B, Hatziioannou T, McKeating JA, Bieniasz PD, Rice CM: Claudin-1 is a hepatitis $C$ virus co-receptor required for a late step in entry. Nature 2007, 446:801-5

58. Meertens L, Bertaux C, Cukierman L, Cormier E, Lavillette D, Cosset FL, Dragic T: The tight junction proteins claudin-1, -6 , and -9 are entry cofactors for hepatitis C virus. J Virol 2008, 82:3555-60.

59. Gao F, Duan X, Lu X, Liu Y, Zheng L, Ding Z, Li J: Novel binding between pre-membrane protein and claudin-1 is required for efficient dengue virus entry. Biochem Biophys Res Commun 2010, 391:952-7.

60. Van Itallie CM, Betts L, Smedley JG, McClane BA, Anderson JM: Structure of the claudin-binding domain of Clostridium perfringens enterotoxin. $J$ Biol Chem 2008, 283:268-74.

61. Saeki R, Kondoh M, Kakutani H, Matsuhisa K, Takahashi A, Suzuki H, Kakamu Y, Watari A, Yagi K: A claudin-targeting molecule as an inhibitor of tumor metastasis. J Pharmacol Exp Ther 2010, 334:576-82.

62. Szasz AM, Tokes AM, Micsinai M, Krenacs T, Jakab C, Lukacs L, Nemeth Z, Baranyai Z, Dede K, Madaras L, Kulka J: Prognostic significance of claudin expression changes in breast cancer with regional lymph node metastasis. Clin Exp Metastasis 2011, 28:55-63.

63. Merikallio H, Kaarteenaho R, Pääkkö P, Lehtonen S, Hirvikoski P, Mäkitaro R, Harju T, Soini Y: Zeb1 and twist are more commonly expressed in metastatic than primary lung tumours and show inverse associations with claudins. J Clin Pathol 2010, 1(64):136-140.

64. Bekker V, Chanock SJ, Yeager M, Hutchinson AA, von Hahn T, Chen S, Xiao N, Dotrang M, Brown M, Busch MP, Edlin BR, Rice CM, O'Brien TR Genetic variation in CLDN1 and susceptibility to hepatitis $C$ virus infection. J Viral Hepat 2010, 17:192-200.

65. Vermeer PD, Denker J, Estin M, Moninger TO, Keshavjee S, Karp P, Kline JN, Zabner J: MMP9 modulates tight junction integrity and cell viability in human airway epithelia. Am J Physiol Lung Cell Mol Physiol 2009, 296:L751-62.

66. Rejman J, Di Gioia S, Bragonzi A, Conese M: Pseudomonas aeruginosa infection destroys the barrier function of lung epithelium and enhances polyplex-mediated transfection. Hum Gene Ther 2007, 18:642-52.

67. Gillrie MR, Krishnegowda G, Lee K, Buret AG, Robbins SM, Looareesuwan S, Gowda DC, Ho M: Src-family kinase dependent disruption of endothelial barrier function by Plasmodium falciparum merozoite proteins. Blood 2007, 110:3426-35

68. Cohen TS, Gray Lawrence G, Margulies SS: Cultured alveolar epithelial cells from septic rats mimic in vivo septic lung. PLoS One 2010, 5:e11322.

69. Wray C, Mao Y, Pan J, Chandrasena A, Piasta F, Frank JA: Claudin-4 augments alveolar epithelial barrier function and is induced in acute lung injury. Am J Physiol Lung Cell Mol Physiol 2009, 297:L219-27.

70. Xia XM, Wang FY, Wang ZK, Wan HJ, Xu WA, Lu H: Emodin enhances alveolar epithelial barrier function in rats with experimental acute pancreatitis. World J Gastroenterol 2010, 16:2994-3001.

71. Jang AS, Concel VJ, Bein K, Brant KA, Liu S, Pope-Varsalona H, Dopico RA Jr, Di YP, Knoell DL, Barchowsky A, Leikauf GD: Endothelial Dysfunction and Claudin 5 Regulation during Acrolein-induced Lung Injury. Am J Respir Cell Mol Biol 2011, 44:483-490.

72. Kilpatrick LE, Standage SW, Li H, Raj NR, Korchak HM, Wolfson MR, Deutschman CS: Protection against sepsis-induced lung injury by selective inhibition of protein kinase C-\{delta\} (\{delta\}-PKC). J Leukoc Biol 2011, 89:3-10

73. Koizumi J, Kojima T, Ogasawara N, Kamekura R, Kurose M, Go M, Harimaya A, Murata M, Osanai M, Chiba H, Himi T, Sawada N: Protein kinase $C$ enhances tight junction barrier function of human nasal epithelial cells in primary culture by transcriptional regulation. $\mathrm{Mol}$ Pharmacol 2008, 74:432-42.

74. Kobayashi K, Miwa H, Yasui M: Inflammatory mediators weaken the amniotic membrane barrier through disruption of tight junctions. $J$ Physiol 2010, 588:4859-4869.

75. Bouvry D, Planès C, Malbert-Colas L, Escabasse V, Clerici C: Hypoxiainduced cytoskeleton disruption in alveolar epithelial cells. Am J Respir Cell Mol Biol 2006, 35:519-27.

76. Koto T, Takubo K, Ishida S, Shinoda H, Inoue M, Tsubota K, Okada Y, Ikeda E: Hypoxia disrupts the barrier function of neural blood vessels through 
changes in the expression of claudin-5 in endothelial cells. Am J Pathol 2007, 170:1389-97.

77. Kieran NE, Doran PP, Connolly SB, Greenan MC, Higgins DF, Leonard M, Godson C, Taylor CT, Henger A, Kretzler M, Burne MJ, Rabb H, Brady HR: Modification of the transcriptomic response to renal ischemia/reperfusion injury by lipoxin analog. Kidney Int 2003, 64:480-492.

78. Strieter RM: Pathogenesis and natural history of usual interstitial pneumonia: the whole story or the last chapter of a long novel. Chest 2005, 128:5265-5325.

79. Rodewald M, Herr D, Fraser HM, Hack G, Kreienberg R, Wulff C: Regulation of tight junction proteins occludin and claudin 5 in the primate ovary during the ovulatory cycle and after inhibition of vascular endothelial growth factor. Mol Hum Reprod 2007, 13:781-9.

80. McDonagh D, Vollmer RT, Shelburne JD: Intercellular junctions and tumor behavior in lung cancer. Mod Pathol 1991, 4:436-40

81. Paschoud S, Bongiovanni M, Pache JC, Citi S: Claudin-1 and claudin-5 expression patterns differentiate lung squamous cell carcinomas from adenocarcinomas. Mod Pathol 2007, 20:947-54.

82. Moldvay J, Jäckel M, Páska C, Soltész I, Schaff Z, Kiss A: Distinct claudin expression profile in histologic subtypes of lung cancer. Lung Cancer 2007, 57:159-67.

83. Sormunen R, Pääkkö P, Kaarteenaho-Wiik R, Soini Y: Differential expression of adhesion molecules in lung tumours. Histopathology 2007, 50:282-4.

84. Chao YC, Pan SH, Yang SC, Yu SL, Che TF, Lin CW, Tsai MS, Chang GC, Wu CH, Wu YY, Lee YC, Hong TM, Yang PC: Claudin-1 is a metastasis suppressor and correlates with clinical outcome in lung adenocarcinoma. Am J Respir Crit Care Med 2009, 179:123-33.

85. Takehara M, Nishimura T, Mima S, Hoshino T, Mizushima T: Effect of claudin expression on paracellular permeability, migration and invasion of colonic cancer cells. Biol Pharm Bull 2009, 32:825-31.

86. Miyamori $H$, Takino $T$, Kobayashi $Y$, Tokai $H$, Itoh $Y$, Seiki M, Sato H: Claudin promotes activation of pro-matrix metalloproteinase- 2 mediated by membrane-type matrix metalloproteinases. J Biol Chem 2001, 276:28204-11.

87. Singh $A B$, Harris $R C$ : Epidermal growth factor receptor activation differentially regulates claudin expression and enhances transepithelial resistance in Madin-Darby canine kidney cells. J Biol Chem 2004, 279:3543-52.

88. Zhang Z, Stiegler AL, Boggon TJ, Kobayashi S, Halmos B: EGFR-mutated lung cancer: a paradigm of molecular oncology. Oncotarget 2010, 1:497-514.

89. Mullin JM, Leatherman JM, Valenzano MC, Huerta ER, Verrechio J, Smith DM, Snetselaar K, Liu M, Francis MK, Sell C: Ras mutation impairs epithelial barrier function to a wide range of nonelectrolytes. Mol Biol Cell 2005, 16:5538-50.

90. Jin G, Kim MJ, Jeon HS, Choi JE, Kim DS, Lee EB, Cha SI, Yoon GS, Kim CH, Jung TH, Park JY: PTEN mutations and relationship to EGFR, ERBB2, KRAS, and TP53 mutations in non-small cell lung cancers. Lung Cancer 2010, 69:279-83.

91. Osaki M, Oshimura M, Ito H: PI3K-Akt pathway: its functions and alterations in human cancer. Apoptosis 2004, 9:667-76.

92. Langlois MJ, Bergeron S, Bernatchez G, Boudreau F, Saucier C, Perreault N, Carrier JC, Rivard N: The PTEN Phosphatase Controls Intestinal Epithelial Cell Polarity and Barrier Function: Role in Colorectal Cancer Progression. PLoS One 2010, 5:e15742.

93. Araki K, Ishii G, Yokose T, Nagai K, Funai K, Kodama K, Nishiwaki Y, Ochiai A: Frequent overexpression of the c-kit protein in large cell neuroendocrine carcinoma of the lung. Lung Cancer 2003, 40:173-80

94. Schmalhofer O, Brabletz S, Brabletz T: E-cadherin, beta-catenin, and zeb1 in malignant progression of cancer. Cancer Metastasis Rev 2009, 28:151-66.

95. De Wever O, Pauwels P, De Craene B, Sabbah M, Emami S, Redeuilh G, Gespach C, Bracke M, Berx G: Molecular and pathological signatures of epithelial-mesenchymal transitions at the cancer invasion front. Histochem Cell Biol 2008, 130:481-494.

96. Peinado H, Olmeda D, Cano A: Snail, ZEB and bHLH factors in tumour progression; and alliance against the epithelial phenotype. Nature Rev Cancer 2007, 7:415-428

97. Angelow S, Ahlstrom R, Yu AS: Biology of claudins. Am J Physiol Renal Physiol 2008, 295:F867-76.
98. Gorin MA, Pan Q: Protein kinase $\mathrm{C}$ epsilon: an oncogene and emerging tumor biomarker. Mol Cancer 2009, 8:9.

99. French AD, Fiori JL, Camilli TC, Leotlela PD, O'Connell MP, Frank BP, Subaran S, Indig FE, Taub DD, Weeraratna AT: PKC and PKA phosphorylation affect the subcellular localization of claudin-1 in melanoma cells. Int J Med Sci 2009, 6:93-101.

100. Stamatovic SM, Dimitrijevic OB, Kepp RF, Andjelkovic AV: Protein kinase Ca-RhoA cross talk in CCL2-induced alterations in brain endothelial permeability. J Biol Chem 2006, 281:8379-8388.

101. Aono S, Hirai Y: Phosphorylation of claudin-4 is required for tight junction formation in a human keratinocyte cell line. Exp Cell Res 2008, 314:3326-39.

102. Itoh M, Furuse M, Morita K, Kubota K, Saitou M: Direct binding of three tight junction-associated MAGUKs, ZO-1, ZO-2 and ZO-3, with the $\mathrm{COOH}$ termini of claudins. J Cell Biol 1999, 147:1351-6136.

103. Betanzos A, Huerta M, Lopez-Bayghen E, Azuara E, Amerena J, GonzalezMariscal L: The tight junction protein ZO-2 associates with Jun, Fos and C/EBP transcription factors in epithelial cells. Exp Cell Res 2004, 292:51-66.

104. Yao Q, Cao S, Li C, Mengesha A, Low P, Kong B, Dai S, Wei M: Turn a diarrhoea toxin into a receptor-mediated therapy for a plethora of CLDN-4-overexpressing cancers. Biochem Biophys Res Commun 2010, 398:413-9.

105. Gao Z, Xu X, McClane B, Zeng Q, Litkouhi B, Welch WR, Berkowitz RS, Mok SC, Garner El: C-Terminus of Clostridium perfringens Enterotoxin Downregulates CLDN4 and Sensitizes Ovarian Cancer Cells to Taxol and Carboplatin. Clin Cancer Res 2011, 17:1065-1074.

106. Mimura T, Ito A, Sakuma T, Ohbayashi C, Yoshimura M, Tsubota N, Okita Y, Okada M: Novel marker D2-40, combined with calretinin, CEA, and TTF-1: an optimal set of immunodiagnostic markers for pleural mesothelioma. Cancer 2007, 109:933-8.

107. Soini Y, Kinnula V, Kahlos K, Pääkkö P: Claudins in differential diagnosis between mesothelioma and metastatic adenocarcinoma of the pleura. J Clin Pathol 2006, 59:250-4.

108. Davidson B, Zhang Z, Kleinberg L, Li M, Flørenes VA, Wang TL, Shih leM: Gene expression signatures differentiate ovarian/peritoneal serous carcinoma from diffuse malignant peritoneal mesothelioma. Clin Cancer Res 2006, 12:5944-50.

109. Kleinberg L, Holth A, Fridman E, Schwartz I, Shih leM, Davidson B: The diagnostic role of claudins in serous effusions. Am J Clin Pathol 2007, 127:928-37.

110. Facchetti F, Gentili F, Lonardi S, Bercich L, Santin A: Claudin-4 in mesothelioma diagnosis. Histopathology 2007, 51:261-3.

111. Kaneda K, Miyamoto K, Nomura S, Horiuchi T: Intercellular localization of occludins and ZO-1 as a solute transport barrier of the mesothelial monolayer. J Artif Organs 2006, 9:241-50.

112. Markov AG, Voronkova MA, Volgin GN, Yablonsky PK, Fromm M, Amasheh S: Tight junction proteins contribute to barrier properties in human pleura. Respir Physiol Neurobiol 2011, 175:331-335.

113. Travis WD, Brambilla E, Noguchi M, Nicholson AG, Geisinger KR, Yatabe $Y$, Beer DG, Powell CA, Riely GJ, Van Schil PE, Garg K, Austin JH, Asamura H, Rusch WW, Hirsch FR, Scagliotti G, Mitsudomi T, Huber RM, Ishikawa Y, Jett J, Sanchez-Cespedes M, Sculier JP, Takahashi T, Tsuboi M, Vansteenkiste J, Wistuba I, Yang PC, Aberle D, Brambilla C, Flieder D, Franklin W, Gazdar A, Gould M, Hasleton P, Henderson D, Johnson B, Johnson D, Kerr K, Kuriyama K, Lee JS, Miller VA, Petersen I, Roggli V, Rosell R, Saijo N, Thunnissen E, Tsao M, Yankelewitz D: International association for the study of lung cancer/american thoracic society/european respiratory society international multidisciplinary classification of lung adenocarcinoma. J Thorac Oncol 2011, 6:244-85.

114. Klamp T, Schumacher J, Huber G, Kühne C, Meissner U, Selmi A, Hiller T, Kreiter S, Markl J, Türeci Ö, Sahin U: Highly specific auto-antibodies against claudin-18 isoform 2 induced by a chimeric $\mathrm{HBCAg}$ virus-like particle vaccine kill tumor cells and inhibit the growth of lung metastases. Cancer Res 2011, 71:516-27.

doi:10.1186/1465-9921-12-70

Cite this article as: Soini: Claudins in lung diseases. Respiratory Research 2011 12:70. 